\title{
La relación entre acto intencional, significación e intuición complementadora husserlianos y los niveles del significar semánticos
}

\author{
The relation between intentional act, meaning and Husserlian \\ supplementary intuition and the levels of semantic meaning
}

Ígor Rodríguez-Iglesias

Universidad de Huelva, España

\begin{abstract}
Resumen: Este artículo describe tres conceptos de Husserl: acto intencional, significación e intuición complementadora, que se ponen en relación con la semántica estructural. En este trabajo defiendo que estos tres conceptos adelantan los tipos de contenido definidos en Semántica posteriormente, con J. Lyons y E. Coseriu: sentido, designación/referencia y significado. Asimismo, se muestra una teoría del signo husserliana comparada con otras conceptuaciones contemporáneas al filósofo. Se destaca la importancia para los desarrollos ulteriores de lo que será la Semántica como ciencia lingüística

Palabras clave: semántica, filosofía del lenguaje, signo lingüístico, Husserl, significado.

Abstract: This article describes three concepts of Husserl: intentional act, meaning and supplementary intuition. In this paper I argue that these three concepts advance the types of content defined in Semantics later, with J. Lyons and E. Coseriu: sense, designation / reference and meaning. Likewise, a theory of the Husserlian sign is compared with other contemporary concepts. The importance for the further developments of what will be the Structural Semantics is highlighted.
\end{abstract}

Keywords: semantics, philosophy of language, linguistic sign, Husserl, meaning.

\section{Introdución}

En el presente estudio pongo en relación acto intencional, intuición complementadora y significación propuestas por Edmond Husserl (1902) en sus Investigaciones lógicas, con los tipos de contenido, o niveles del significar, perfilados en Semántica por John Lyons $(1968,1977)$ y Eugenio Coseriu (1978). No se trata de establecer una relación directa entre el filósofo y los lingüistas, sino de observar cómo en aquel se anticipan conceptuaciones fundamentales de la Semántica estructural, contenidas ya en G. Frege (1892), discutidas en Lyons (1977: 199). Lo que se dirá, pues, es que las conceptuaciones lingüísticas tienen una base filosófica previa, que los filósofos de finales del siglo XIX y principios del XX ya advierten. Los temas en torno al significado y la referencia están presentes en estos filósofos coetáneos, Husserl y Frege, que darán lugar a escuelas de pensamiento muy 
diferenciadas, como la fenomenología y la filosofía analítica, pero que, como ha advertido M. Dummett (Pataut, 1998: 126):

(...) a principios de siglo [XX], por ejemplo, en el momento en que Husserl publicó sus Investigaciones lógicas, no existía todavía la fenomenología como escuela. No existía todavía la filosofía analítica como escuela. Había muchas corrientes y lo normal hubiera sido situar a Frege y Husserl en lugares bastante cercanos, aunque su descendencia haya sido tan divergente.

A. G. Vigo (2008: 45), apoyándose en J. N. Mohanty (1982), sostiene que ambos pensadores llegaron en paralelo a las mismas conceptuaciones respecto del significado.

A pesar de las semejanzas de los modelos explicativos desarrollados por Frege y Husserl en el ámbito de la teoría del significado, y contra lo que se supuso en algún momento, no parece haber habido, desde el punto de vista histórico, una influencia directa de Frege y Husserl, sino que, con toda probabilidad, ambos pensadores llegaron a resultados comparables, en algunos aspectos centrales, trabajando de modo paralelo.

Así, sentido, designación o referencia y significado tienen su correlato filosófico en las categorizaciones de Husserl mencionadas, de tal modo que los planteamientos freguianos son continuados o desarrollados en la filosofía fenomenológica de Husserl, cuyas influencias en Coseriu son evidentes (cf. Báez San José, 1996 y 2000), y en las respectivas semánticas de Lyons y Coseriu.

El segundo apartado de este trabajo supone una explicación sobre tales conceptos husserlianos. En el tercer apartado, realizo tal comparación, poniendo de relieve sus implicaciones y alcances. En el cuarto apartado, por lo que de relevante tiene el signo lingüístico concebido por Husserl para el asunto en cuestión, desarrollo sus conceptualizaciones al respecto, lo que también permite comparar estas con las de otros contemporáneos al filósofo moravo, como F. Saussure, K. Bühler o L. Hjelmslev, quien desarrolló una lingüística plenamente estructuralista. Finalmente, en la conclusión, se advierte de la importancia del correlato filosóficolingüístico, de su repercusión sobre las concepciones del signo en K. Baldinger (1957, 1970) y K. Heger $(1969,1974)$, así como para la descripción de cómo se sistematiza lo que es referenciado y lo designativo en el ámbito del contenido del sistema de la lengua, y las implicaciones para las oposiciones semánticas.

\section{Acto intencional, significación e intuición complementadora en Husserl}

El filósofo alemán indica que:

las vivencias del significar son actos, y lo significativo de cada acto particular reside justamente en la vivencia de acto y no en el objeto, y reside en lo que hace de ella una vivencia intencional, «dirigida» a objetos (1901: 473).

Por lo tanto,

el concepto de acto, en el sentido de vivencia intencionall, define una importante unidad genérica en la esfera de las vivencias (tomadas en pureza fenomenológica) y [...], por ende, la inclusión de las vivencias

\footnotetext{
${ }^{1}$ Nota de E. Husserl.
} 
significativas en este género proporciona en realidad una valiosa característica de las mismas (1901: 474).

Es imprescindible que tengamos en cuenta que "todo acto o es una representación o tiene por base representaciones" (1901: 474) o, como el mismo autor moravo reformula, "todo acto, o es de suyo una representación, o está fundado en una o varias representaciones" (1901: 556). Además, hemos de advertir para la clarificación del concepto de acto intencional que este adjetivo

indica el carácter esencial común a la clase de vivencias que se trata de definir, la propiedad intención, el referirse a algo objetivo en el modo de la representación o en cualquier modo análogo (1901: 498).

Este término, el de intención, "presenta la naturaleza propia de los actos bajo la imagen del apuntar hacia" (1901: 499). Por otra parte, "la idea de actividad debe quedar excluida en absoluto", en lo que respecta a acto (ídem).

¿Qué relación hay entre el acto intencional y la significación? Ésta es el resultado de la "abstracción ideatoria" de la esencia significativa del acto, que es inherente al acto:

Siempre que se trate de actos, que funcionen o puedan funcionar como actos de prestar significación a las expresiones [...] hablaremos [...] de la esencia significativa del acto. Su abstracción ideatoria da por resultado la significación (1901: 525).

Lo significativo de los actos que prestan significación a las expresiones coincide con su esencia intencional y este hecho significativo es lo que conforma en tales actos el correlato fenomenológico real de la significación ideal (1901: 527).

La presencia de la intuición, entonces, "tiene por efecto determinar ese elemento común de la significación, que es indeterminado en su abstracción", de tal modo que "la intuición le da la determinación de la dirección objetiva y con ella su última diferencia. Esto, empero, no exige que resida en la intuición una parte de la significación misma" (1901: 612). Efectivamente, existe una

antítesis entre la intuición y la significación. La intuición como percepción o imaginación (lo mismo si es categorial que sensual, si es adecuada o inadecuada) es opuesta al mero pensamiento, como mero mentar significativo (1901: 745).

La intuición, pues, es un elemento complementador de la significación en el caso de actos en los que la concreción está ausente en menor o mayor grado, satisfaciendo en su medida lo intencionado.

Un nombre como ventana, por ejemplo, apunta hacia el objeto ventana. Realmente, quien actualiza lo que, más tarde, K. Bühler (1934) Ilamará función representación, es el/la hablante, de ahí la relación predicativa del signo lingüístico con la realidad extralingüística (Espinosa García, 1995: 26), pues como indica Valerio Báez San José "ningún elemento lingüístico fuera del hablar pueda tener función representativa, pues esta la instaura el hablante" (Báez San José, 1996: 141). Esta instauración es simultánea a lo que la significación provee: la abstracción ideatoria correspondiente, que subyace a toda esencia significativa inherente al acto mismo y que conforma el ideal de toda ventana. Al tratarse de un hecho concreto, la intuición no complementa la significación. Pero si se tratase de una metáfora como 
ventana al pasado o ventana de conocimiento, la intuición complementará, llenará, saturará, lo que la significación no puede por sí sola completar, dada la falta de concreción de tales asertos.

\section{El acto intencional, la significación y la intuición complementadora ante los niveles del significar}

La distinción establecida por Husserl entre intuición y significación, inherente al acto intencional, y este mismo, está anticipando dos formulaciones importantes para la Lingüística estructuralista, que se desarrollará a lo largo del siglo XX. De un lado, las funciones del hablar de K. Bühler (1934), especialmente, lo referido al signo lingüístico como tal, en los términos apuntados más arriba, es decir, la relación que establece el hablante entre el signo y el referente. Por otro lado, los tipos de contenido o niveles del significar que perfilará la Semántica estructuralista, con el objeto de dilucidar lo significativo y lo designativo en función de la dicotomía lengua/habla que le sirve de base para sus fundamentos teóricos. Estas repercusiones de Husserl son de calado, porque alumbran toda una serie de implicaciones desde el punto de vista de la Lingüística y, en concreto, de la Semántica, con respecto a la sistematización en el plano del contenido de todo lo que le es designativo a la lengua.

En este sentido, y procedente igualmente de la Filosofía del Lenguaje, la lingüística estructuralista ha dilucidado varios niveles de contenido semántico o del significar: sentido, referencia y significado, que es explícito en la obra de J. Lyons (1977). En paralelo, E. Coseriu (1978) ha hablado de designación, en lugar de referencia (que son equivalentes), diferenciando entre designación real (la referencia que establece el/la hablante en la interacción comunicativa, actualizando mediante tal referencialidad la función representativa del signo lingüístico) y la designación potencial (la conceptuación del mundo, la representación mental de lo referenciado, que ya no es interaccional, sino constante, abstracto, aunque aún comunicativo y no lingüísticamente sistemático) (Casas 2002). Esto tiene implicaciones desde el punto de vista del plano del contenido del signo lingüístico, del significado, y de su sustancia, su sentido, de tal modo que el significado designa potencialmente y el sentido designa referencialmente, o denotativamente, al corresponder la denotación de J. S. Mill (1873) la referencia de Lyons (1977) y la designación real de Coseriu (1978), tal y como ha establecido Casas (op. cit.). Ello implica que la connotación de Mill, que se ha opuesto en las gramáticas escolares pretendidamente lingüísticas del siglo XX a denotación -dicotomía de base filosófica y nocional-, corresponde al sentido, es decir, a la sustancia del contenido y, por tanto, al ámbito comunicativo, concreto y dinámico de todo hablar, en que se actualiza lo que es sistemático, abstracto y estático. Es claro que la designación potencial de Coseriu (1978) tiene una correspondencia con el concepto de K. Baldinger y K. Heger, cuya separación de lo que es propio del significado y lo que es propio de lo extralingüístico en el ámbito del contenido supone una salto cualitativo en la concepción del signo lingüístico, concebido en la llamada Antigüedad y que ha sobrevivido hasta hoy, con importante repercusiones en el siglo XX para la ciencia lingüística estructuralista.

Una comparativa cronológica de las diferentes concepciones de signo lingüístico desde la Grecia clásica a la actualidad (Rodríguez-Iglesias, 2017) permite observar 
cómo Baldinger y Heger establecen esta distinción fundamental, no contemplada por Ullman (1951), en el seno de la ciencia lingüística, ni por Ogden y Richards (1923), desde la filosofía del lenguaje, pero que, como defendemos, ya era observada en Husserl a través de la diferencia entre significación e intuición complementadora.

\begin{tabular}{|c|c|c|c|c|c|c|c|c|c|}
\hline \multicolumn{3}{|c|}{ Dicotómica } & \multicolumn{3}{|l|}{ Triangular } & \multicolumn{2}{|c|}{ Trapezoidal } & \multirow{2}{*}{$\begin{array}{l}\text { Pentagonal } \\
\text { Raible }\end{array}$} & \multirow{2}{*}{$\begin{array}{l}\text { Heptagonal } \\
\text { Casas }\end{array}$} \\
\hline Aristóteles & Estoicos & Saussure & Modistas & $\begin{array}{l}\text { Oggdeny } \\
\text { Richards }\end{array}$ & Ullmann & Baldinger & Heger & & \\
\hline 5.IV & 55. III- $\ldots$ & 1916 & $5 . X$ & 1922 & 1962 & $\begin{array}{l}1957 \\
(1970)\end{array}$ & $\begin{array}{l}1969 \\
(1974)\end{array}$ & 1983 & 2002 \\
\hline $\begin{array}{l}\text { Lo que está } \\
\text { en el alma }\end{array}$ & $\begin{array}{l}\text { Sgdo. } \\
\text { Ste. }\end{array}$ & $\begin{array}{l}\text { Concepto } \\
\text { mental } \\
\text { Imagen } \\
\text { acústica }\end{array}$ & $\begin{array}{l}\text { Modi } \\
\text { intelligendi } \\
\text { (aglutina } \\
\text { significado, } \\
\text { pensamiento, } \\
\text { concepto) } \\
/ \\
\text { Modi } \\
\text { significandi } \\
\text { (significante) } \\
\text { / } \\
\text { Modi essendi } \\
\text { (referenta) }\end{array}$ & $\begin{array}{l}\text { Sgdo. } \\
/ \\
\text { Ste. } \\
/ \\
\text { Cosa }\end{array}$ & $\begin{array}{l}\text { Sgdo. } \\
\text { Ste. } \\
\text { Cosa }\end{array}$ & $\begin{array}{l}\text { Sggdo. } \\
\text { Concepto } \\
/ \\
\text { Ste. } \\
\text { Cosa }\end{array}$ & $\begin{array}{l}\text { Sgdo. } \\
\text { Concepto } \\
/ \\
\text { Ste. } \\
/ \\
\text { Cosa }\end{array}$ & $\begin{array}{l}\text { Sgdo. } \\
\text { Concepto } \\
/ \\
\text { Ste. } \\
\text { Referencia } \\
\text { / } \\
\text { Cosa }\end{array}$ & $\begin{array}{l}\text { Sgado. } \\
\text { Concepto } \\
\text { Ste. } \\
\text { Referencia } \\
\text { Sentido } \\
\text { Cosa }\end{array}$ \\
\hline
\end{tabular}

La intuición complementadora ya está anticipando la designación potencial de Coseriu (1978) y el concepto de Baldinger (1957) y Heger (1969), en tanto que supone una representación mental que ha de ser constante. No estamos diciendo que sea exactamente lo mismo, pues las pretensiones del filósofo y las de los lingüistas son totalmente diferentes. Sin embargo, el alcance de estas conceptualizaciones sí permite ver en Husserl un antecedente en la dilucidación de los tipos de contenido lingüísticos. Esto es más claro si se ponen en relación la significación y el significado, de un lado, y el acto intencional y la referencia/designación real/denotación, de otro, pues permite ver cómo Husserl está diferenciando entre lo interaccional y lo no interaccional, y en este ámbito, entre lo que es propio del lenguaje y lo que no. No obstante, significado no está definido en los términos de la semántica estructuralista, es decir, como un valor semántico formalizado intralingüísticamente en oposición a otros significados (Casas 2002), pues la teoría del signo de Husserl está definida en función de disquisiciones filosóficas. 


\section{El signo según Husserl}

Para Husserl, "todo signo es signo de algo, pero no todo signo tiene una significación, un "sentido», que esté «expresado» por el signo" (1900: 233). La concepción del filósofo moravo es más amplia de la que se maneja en lingüística e incluye las señales y los símbolos, que dentro del signo distinguirá este autor y, en esta línea de semiótica, antes aparece en Ch. Pierce (1894). La clave en Husserl estará en la "función significativa" (ibíd.), que es la que nos interesará para dilucidar de entre los distintos tipos de signos el lingüístico dentro de la concepción husserliana. Así,

los signos, en el sentido de indicaciones (señales, notas, distintivos, etc.), no expresan nada, a no ser que, además de la función indicativa, cumplan una función significativa (1900: 233).

De los signos indicativos o señalativos, dice Husserl, "distinguiremos los signos significativos, las expresiones" (las cursivas son de Husserl).

Si atendemos a lo que indica Husserl,

todo discurso y toda parte de discurso, así como todo signo, que esencialmente sea de la misma especie, es una expresión; sin que importe nada que el discurso sea verdaderamente hablado - esto es, enderezado a una persona con propósito comunicativo- o no (1900: 238).

Cuando Husserl habla de "expresión" no se refiere a la unidad comunicativa praguense (cf. Daneš, 1964), ya que esta es únicamente discursiva y no cualquier signo, como se desprende del párrafo anterior. Para la lingüística estructuralista, a la expresión o enunciado subyace el signo, la forma y no la sustancia de la que habló Saussure (1916: 161 y 171) y que conduce la teorización de glosemática de L. Hjelmslev (1943), de la Escuela de Praga (Trnka, Vachek, Trubetzkoy, Mathesius y Jakobson, 1971) y de desarrollos funcionalistas como el de la Teoría de los Esquemas Sintáctico-Semánticos de V. Báez de San José (2000) y sus seguidores (Espinosa García, 1995; Díaz Hormigo, 1998), entre otros.

Aquí se nos presenta otra separación metodológica husserliana que conducirá en la lingüística estructuralista el citado teorizar con la oposición forma/sustancia como sustento epistémico. Husserl, en constante huida de los equívocos terminólogicos, diferencia entre expresión hic et nunc, la propia del acto del hablar, y expresión in specie, siempre constante, subyacente, pues, al momento discursivo. Salvando las distancias y los alcances, recuerda al desarrollo conceptual de Hjelmslev (1943: 85-87) cuando concibe el signo lingüístico como forma del contenido (significado) y forma de la expresión (significante), explicitado en el hablar a través de sus respectivas sustancias. Hjelmslev se refiere a la sustancia del contenido como los pensamientos, pero los desarrollos de la semántica de Lyons (1977), Coseriu (1978), Baldinger (1957), Heger (1969) y otros -posteriores, pues, al lingüista danés- nos permiten asimilar la sustancia del contenido al sentido e, incluso diferenciar los otros niveles del significar en la sustancia del contenido, de tal modo que el significado (forma del contenido), que designa, se explicita en el sentido, que denota. Su correlato en el significante, en función del nivel de indagación y formalización lingüísticas, es fonema/sonido, morfema/morfo u oración/enunciado. 
La expresión (tanto la eventual como la intemporal, esto es, el enunciado y lo que le subyace abstracta, estática y no comunicativamente) mantiene, según explica Husserl, una relación de "idealidad" con la significación, donde también el autor diferencia lo eventual de lo intemporal: el juicio de valor, la vivencia de dar significación, el sentido unido a la expresión hic et nunc frente a la significación, el contenido, que para Husserl será lo mismo. En este punto, adviértase cómo significación es usado por E. Coseriu (1981) en el sentido de relación estructural entre los significados de los signos. Lo importante es que se dilucida en Husserl lo que en Saussure se llamará explícitamente significante y significado, distinción terminológica

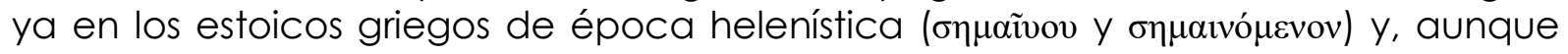

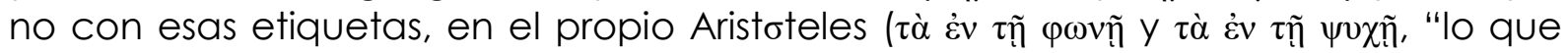
está en la voz" y "lo que está en el alma", respectivamente) (Coseriu, 1981:21).

En Husserl también está explícita el $\pi \rho \tilde{\alpha} \gamma \mu \alpha$ (la cosa) de los estoicos: "Toda expresión no sólo dice algo, sino que también lo dice acerca de algo", distinguiendo, pues, "entre lo que significa o "dice» y aquello acerca de lo cual lo dice" (1900: 249).

Hay, por tanto, en Edmund Husserl una concepción triádica del signo: expresiónsignificación-cosa. Pero, adviértase, que "quienes entran en relación no son [...] la palabra [...y la cosa], sino las vivencias de actos", donde

no hay [...] ningún objeto, sino la percepción, un estado de conciencia determinado de tal o cual manera; luego el acto de conocimiento que hay en la vivencia está fundado sobre el acto de percepción (1901: 616617).

\section{Otras concepciones del signo: Saussure, Hjelmslev y Bühler}

El libro que los alumnos de F. de Saussure publicaron tras la muerte del maestro ginebrino, el Curso de lingüística general (1916), recoge las enseñanzas de tres cursos (1907-1908, 1908-1909 y 1910-1911). Nos interesa aquí la segunda lección del tercer curso. En ella, Saussure aborda el signo lingüístico tal y como hemos anticipado, distinguiendo entre dos elementos inherentes al mismo: el concepto y la imagen acústica, que el propio Saussure sustituirá por los ya referidos de significado y significante (1916: 104), respectivamente, sólo por "una importante cuestión terminológica" (ibíd., p. 103). "El signo lingüístico es por tanto una entidad psíquica de dos caras", dice el lingüista suizo, pero, advierte, "no une una cosa y un nombre, sino un concepto y una imagen acústica" (ibíd., p. 102), elementos que "están íntimamente unidos y se requieren recíprocamente (ibíd., p. 103). Es interesante aquí el apunte del traductor de la edición española, Mauro Armiño (Saussure, 2006: 103), en nota a pie de página:

La definición saussureana de signo ha dado lugar a diversas polémicas, justificadas por la ambigüedad; en este pasaje, y según la referencia, signo parece querer aludir a la entidad más pequeña que la frase, el vocablo quizá. Para Godel, la definición va bien con toda entidad lingüística, monema, sintagma, proposición, frase; para Buyssens, el signo lingüístico (saussureano) sería el segmento más pequeño que, por la pronunciación o por la significación, permite dos operaciones complementarias: asociar frases diferentes y oponer frases semejantes. 
Volveremos a Saussure y a Husserl. L. Hjelmslev centra ahora nuestra atención. El signo, dice el lingüista danés, "es una entidad generada por la conexión entre una expresión y un contenido" (1943: 73), elementos ya presentes en los autores señalados. En referencia a uno de ellos, a Saussure, Hjelmslev indica que a partir de este "se ha afirmado con frecuencia la existencia de una interdependencia entre ciertos elementos dentro de una misma lengua", reconociendo por parte del danés dependencias mutuas (interdependencias: solidaridad/complementaridad), unilaterales (determinaciones: selección/especificación) y otras de mayor libertad (constelaciones: combinaciones/autonomías) (cf. 1943: 41-43). El principio del análisis para Hjelmslev "será el reconocimiento de esas dependencias" (ibíd., p. 46), de tal suerte que "a la dependencia que satisface las condiciones del análisis la llamaremos función" y "a los terminales de una función los llamaremos funtivos, entendiendo por funtivo un objeto que tiene una función con otros objetos. De él se dice que contrae su función", y al funtivo que no es función, lo llama entidad. (ibíd., p. 55). Para el lingüista danés

parece más adecuado usar la palabra signo para designar la unidad que consta de forma de contenido y forma de expresión y que es establecida por la solidaridad que hemos llamado función del signo (ibíd., p. 87).

Esto es,

en virtud de la función de signo, y sólo en virtud de ella, existen sus dos funtivos, que pueden ahora designarse con precisión como forma del contenido y forma de la expresión (ibíd., p. 85).

Discutiendo a Saussure, cuando este dice que "esta combinación produce una forma, no una sustancia" (1916: 161), Hjelmslev (op. cit., p. 76) observa que

\begin{abstract}
en una ciencia que evita postulados innecesarios no hay base para afirmar gratuitamente que la sustancia del contenido (pensamiento) o la sustancia de la expresión (cadena de sonidos) preceda a la lengua en el tiempo o en orden jerárquico, o viceversa. [...] Resulta claro que la sustancia depende de la forma hasta el punto que vive exclusivamente a causa de ella y no puede en ningún sentido decirse que tenga existencia independiente.
\end{abstract}

Así, y al hilo de lo que íbamos diciendo sobre la función de signo y sus dos funtivos, es Hjelmslev quien indica que, "en virtud de la forma del contenido y de la forma de la expresión, y sólo en virtud de ellas, existen respectivamente la sustancia del contenido y la sustancia de la expresión" (1943: 85), pero ya no estaremos en el plano de la lengua. Y he ahí una de las claves de la teoría del lingüista danés, pues, según explica, "la distinción entre expresión y contenido y su interacción en la función de signo es algo básico en la estructura de cualquier lengua", cuyos signos "contienen en sí una forma de la expresión y una forma del contenido" (1943: 87).

K. Bühler, por su parte, basándose en el Órganon de Aristóteles, su órganon. A raíz de esta consideración triádica del signo, presenta Bühler al emisor y al receptor, así como a las cosas, que serán en su Teoría del lenguaje (1934) los objetos y relaciones:

El hecho de que en un sistema de dos clases de los medios de representación del tipo del lenguaje pertenezcan también a las ordenaciones léxicas convenciones sintácticas, no hace sino ampliar el campo de las relaciones de ordenación que encontramos en él. Para 
responder a ello, en el lugar del esquema en que ponía "las cosas», escribimos ahora la doble denominación objetos y relaciones (1934: 50).

Pero el modelo del órganon de Bühler no sólo supone la existencia de un emisor, un receptor y ordenación respecto de objetos y relaciones. Metodológicamente, Bühler presenta gráficamente entre estos tres elementos un círculo y un triángulo, con implicaciones muy importantes: por un lado, para la propia descripción del signo $y$, por otro, porque establece las bases de las funciones del hablar y los elementos de la comunicación:

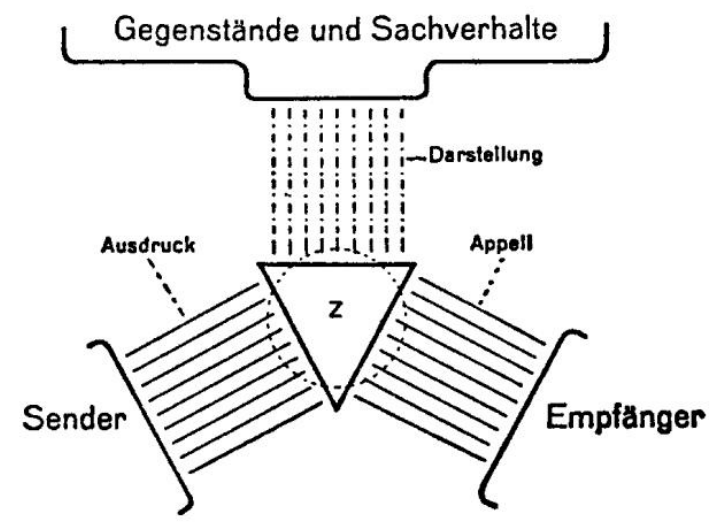

\begin{abstract}
El círculo del centro simboliza el fenómeno acústico concreto. Tres momentos variables en él están llamados a elevarlo por tres veces distintas a la categoría de signo. Los lados del triángulo inserto simbolizan esos tres momentos. El triángulo comprende en un aspecto menos que el círculo (principio de la relevancia abstractiva). En otro sentido, a su vez, abarca más que el círculo, para indicar que lo dado de un modo sensible experimenta siempre un complemento perceptivo. Los grupos de líneas simbolizan las funciones semánticas del signo lingüístico (complejo) (1934: 48).
\end{abstract}

De la concepción bifacial del signo por parte de F. de Saussure se ha predicado una simetría por parte algunos lingüistas (Saussure, 1916: 103, 168; Martinet, 1960: 2223), que otros lingüistas negarán, como S. Karčevskij (1929: 88), cuando afirma que

le signe et la signification ne se recourent pas entièrement, leurs limites en coincident pas dans tous les points: un même signe a plusieurs fonctions, une même signification s'exprime par plusieurs signes.

En la lingüística posterior tendrá consecuencias, pues se negará o se afirmará la existencia de sinónimos absolutos (Casas, 2002: 99).

Otra cuestión es la relativa a la arbitrariedad del signo, propugnada por Saussure (1916: 104), aunque la idea no es suya, como nos advierte Coseriu (1981: 25-26), pues aparece en Aristóteles (384 a. C.-322 a. C), Aulo Gelio (ca. 129-ca. 180 d.C), Boecio (ca. 480-524) y la filosofía escolástica, Julio César Escalígero (1484-1558), Hobbes (1588-1679) y Schottel (1612-1676), entre otros (Coseriu, 1981: 25-26). El caso es que la arbitrariedad es también defendida tanto por Husserl-cuando dice que 
"las palabras no pertenecen a la conexión objetiva que expresa, en este caso a la de la cosa física" (1901: 616)-, como por Hjmeslev (1943: 79):

\begin{abstract}
Reconocemos [...] en el contenido lingüístico, en su proceso, una forma específica, la forma del contenido, que es independiente del sentido y mantiene una relación arbitraria con el mismo, y que le da forma en una sustancia del contenido.
\end{abstract}

Para Bühler la relación también es arbitraria: "Si «hoy» consideramos comparativamente el fonema y la cosa, no resulta ninguna "semejanza entre ambosı". Esto hay que matizarlo, porque no sólo se está refiriendo a la relación entre las cosas y el signo, sino también a "la ordenación de los signos fonéticos" (1934: 49-50), lo que apunta hacia otra característica del signo, su carácter lineal, pero sólo en cuanto al significante, porque el significado le es simultáneo.

\title{
6. A modo de conclusión
}

El signo lingüístico ha tenido implicaciones muy importantes para los desarrollos de la lingüística estructural $y$, por tanto, de la ciencia del lenguaje. Lo que era una conceptuación propia de la Filosofía, cuyas indagaciones se proponían estudiar el pensamiento a través del lenguaje, en el que está parcialmente explicitado, ha arrojado luz y aportado categorías fundamentales para la constitución de una ciencia, la Lingüística, que se hizo científica, a partir de pensar las unidades de la gramática tradicional como signos lingüísticos que se relacionan entre sí.

No sólo es la Filosofía antigua y la llamada medieval, con Aristóteles, los estoicos o los escolásticos, las que son precedentes lejanos del pensamiento lingüístico del siglo $X X$, sino la misma Filosofía que le es contemporánea y gracias a la cual se han desarrollado teorizaciones fundamentales, como las descritas en este artículo.

Husserl constituye un elemento imprescindible, ya que ha ejercido una influencia suficientemente acreditada sobre los lingüistas de la Escuela de Praga, como Karl Bühler, o Eugenio Coseriu en sus concepciones sobre las categorías lingüísticas, tales como el ser en sí, el modo de ser, el ser en otro, etc. Como hemos puesto de relieve, previamente a los inicios de la Semántica, que se convertirá en científica, desde el punto de vista del análisis estructural y funcional, con los desarrollos de Baldinger (1970), Heger (1974) o Coseriu (1978), entre otros, Husserl esbozará conceptualizaciones que anticipan ya los tipos de contenido o niveles del significar a través de sus conceptos acto intencional, intuición complementadora y significación, así como las relaciones entre los mismos.

Es importante reconocer esto, habida cuenta de que la semántica posterior a $C$. K. Reisig (1839) y M. Bréal (1897) -tradicional, analítica-referencial, operacional, preestructural, asociativa y neohumboldtiana- de la primera mitad del siglo XX adolece de ser muy filosófica frente a la Lingüística. Sin embargo, es la semántica estructuralista, plenamente científica, la que ahonda sus raíces no sólo en G. Frege, sino también en E. Husserl, que tuvo el acierto de esbozar unas conceptuaciones que en sus desarrollos ya plenamente al interior de las ciencias del lenguaje tendrán alcances muy importantes para dilucidar la relación predicativa del signo y lo referenciado, lo designativo frente a lo significativo y los tipos de relaciones constantes, ya privativas, ya equipolentes, así como las neutralizables, entre los significados del sistema lingüísticos, las llamadas relaciones semánticas, cuestión esta que permitirá distinguir, como ha demostrado Casas (2011), entre relaciones 
semánticas per se, tales como la sinonimia, la pseudosinonimia, la antonimia, la hipernonimia - hiponimia - cohiponimia y la neutralización, y relaciones pseudosemánticas, estudiadas tradicionalmente como semánticas, tales como la homonimia, la polisemia y el sincretismo.

\section{Bibliografía}

BÁEZ SAN JOSÉ, V. (1990-1991): "Oración y esquema oracional", Anales de la Universidad de Cádiz (Homenaje a Antonio Holgado Redondo), № 7-8, 1, 19901991, pp. 69-86.

BÁEZ SAN JOSÉ, V. (1996): "Desde una lingüística del hablar a una lingüística de las lenguas. A propósito de las funciones del hablar, las funciones de los elementos lingüísticos y las funciones sintagmáticas en las cadenas lingüísticas".I Jornadas de Lingüística. M. CASAS (ed.). Cádiz: Universidad de Cádiz, pp. 135-185.

BALDINGER, K. (1957): Die Semasiologie: Versuch eines Überblicks. Berlin: AkademieVerlag.

BALDINGER, K. (1970): Teoría semántica. Hacia una semántica moderna. Madrid: Ediciones Alcalá.

BRÉAL, M. (1897) : Essai de semantique. Science des significations. París: Hachette.

BÜHLER, K. (1934): Teoría del lenguaje. Madrid: Alianza, 1985.

CASAS, M. (2002): Los niveles del significar. Cádiz: Universidad de Cádiz.

CASAS, M. (2011). "Problemas y criterios lingüísticos subyacentes a una tipología de relaciones en semántica". Lorenzo Hervás, número 20 (extraordinario), junio de 2011, pp. 63-108.

COSERIU, E. (1977): Principios de semántica estructural. Madrid: Gredos.

COSERIU, E. (1999): Lecciones de lingüística general. Madrid: Gredos.

DANEŠ, F. (1964): "A three level approach to syntax". Travaux linguistiques de Prague, 1, pp. 225-240.

DÍAZ HORMIGO, Ma T. (1998): "Sintaxis y semántica de la construcción con sustantivo en posición nuclear", LynX, Annexa 11, Valencia: Universidad de Valencia.

ESCANDELL VIDAL, M. V. (2006): Introducción a la pragmática. Barcelona: Ariel.

ESPINOSA GARCÍA, J. (1995): Estructuras sintácticas transitivas e intransitivas en español. Cádiz: Servicio de Publicaciones de la Universidad de Cádiz.

FREGE, G. (1892): "Über Sinn und Bedeutung", Zeitschrift für Philosophie und philosophische Kritik, 100, pp. 25-50.

HEGER, K. (1966): "La conjugaison objective en français et en espagnol". Langages, Linguistique française. Le verbe et la phrase, sous la direction de Algirdas Julien Greimas et Jean Dubois, 1 année, n. 3, 1966, pp. 19-39.

HEGER, K. (1974): Teoría semántica: hacia una semántica moderna II. Madrid: Ediciones Alcalá.

HJELMSLEV, L. (1943): Prolegómenos a una teoría del lenguaje. Madrid: Gredos, 1971. HUSSERL, E. (1900): Investigaciones lógicas. I. Madrid: Alianza Editorial, 1985.

HUSSERL, E. (1901): Investigaciones lógicas. Il. Madrid: Alianza Editorial, 1982.

KARČEVSKIJ, S. (1929): "Du dualisme assymétrique du signe linguistique", Travaux du Cercle Linguistique de Prague, I, pp. 88-93. 
LYONS, J. (1968): Introduction to Theoretical Linguistics. Cambridge: Cambridge University Press.

LYONS, J. (1977): Semantics. Cambridge: Cambridge Uniersity Press.

MARTINET, A. (1960): Elementos de lingüística general. Madrid: Gredos.

MOHANTY, J. N. (1982): "Husserl and Frege". Husserl. Intentionality and Cognitive Science. H. DREYFUS \& H. HALL (eds.). Cambridge: The MIT Press.

OGDEN, C.K. y RICHARDS, I.A. (1923): The meaning of meaning. Londres: Routledge \& Kegan Paul.

PATAUT, F. (1998): "Una perspectiva antirrealista sobre el lenguaje, el pensamiento, la lógica y la historia de la filosofía analítica: entrevista con Michael Dummett", Teorema, vol. XVII/2, 1998, pp. 115-144.

REISIG, C. K. (1839): "Semasiologie oder Bedeutungslehre". Professor K. Reisig's Vorlesungen über lateinische Sprachwissenschaft. F. HAASE (ed.). Leipzig, pp. 286-307.

RODRÍGUEZ-IGLESIAS, Í. (2017): "Semántica y significado. Concepción heptagonal y relaciones semánticas". Working Paper Lengcom, 13, pp. 1-36.

SAUSSURE, F. (1916): Curso de lingüística general. Madrid: Akal, 2006.

TRNKA, B., J. VACHEK, N. S. TRUBETZKOY, V. MATHESIUS \& R. JAKOBSON (1971): El Círculo de Praga. Barcelona: Anagrama.

ULLMANN, S. (1951): The Principles of Semantics. Glasgow: Glasgow University Publications.

VIGO, A. G. (2008): Arqueologia y aleteiologia y otros estudios heideggerianos, Buenos Aires: Biblos. 